\title{
SUGGESTIONS FOR IMPROVMENTS OF THE RADIATION PROTECTION FOR THE EMERGENCY WORKERS DURING THE FUKUSHIMA NUCLEAR POWER PLANT ACCIDENT
}

\author{
KHALID KHASAWNEH* and KUN-WOO $\mathrm{CHO}^{\dagger}$ \\ *Department of Nuclear and Quantum Engineering, Korea Advanced Institute of Science and Technology \\ ${ }^{\dagger}$ Korea Institute of Nuclear Safety
}

Received March 5, 2014 / 1st Revised June 14, 2014 / Accepted for Publication June 18, 2014

\begin{abstract}
Following the emergency work in Fukushima Daiichi nuclear power plant, more attention was paid for the radiation protection of workers working under severe accident condition. The protection procedure for the emergency workers, including the on-site emergency center, the seismic isolated building and the reestablishment of the radiation protection framework were analyzed to investigate drawbacks and deficiencies which led to adverse effects on the emergency planning and on emergency workers' health and comfort. Those drawbacks were identified and studied, and then suggestions were made to enhance the emergency working condition to avoid any future problems during severe accident emergency work and management.
\end{abstract}

Keywords: Fukushima, Severe accident, Radiation protection, Emergency workers

\section{INTRODUCTION}

The radiation emergency exposure situations are defined by the International Commission on Radiological Protection (ICRP) as 'situations that may occur during the operation of a planned situation, or from a malicious act, or from any other unexpected situation and require urgent action in order to avoid or reduce undesirable consequences'. Where the definition of the occupational exposure is 'Any exposure incurred by the workers in the course of their work, with the exception of excluded exposures and exposures from exempt activities, medical exposure and the background.'[1]

In accordance with the radiation protection principles such as justification, optimization and limitation, and the recommendations of the ICRP, the regulatory requirements on emergency exposure situations were established for countries around the world. For example, in the United States, the Environmental Protection

Author's permanent address: Jordan Atomic Energy commission, P. O. Box 70, Amman 11934, Jordan.
Agency (EPA) guidelines [2] stated that doses to all workers during emergencies should, to the extent practicable, be limited to $50 \mathrm{mSv}$. Higher limits can be justified for special conditions; however the dose resulting from such emergency exposures should be limited to $100 \mathrm{mSv}$ for protecting valuable property, and to $250 \mathrm{mSv}$ for lifesaving activities and the protection of large populations [3]. In Japan, the reference level for the whole body effective dose at the emergency exposure situations was $100 \mathrm{mSvy}^{-1}$ before the Fukushima accident, however it was raised to 250 $\mathrm{mSvy}^{-1}$ during the phase of actual emergency response in order to allow workers to respond to this serious accident. Meanwhile, the value for the lens of eye dose is $300 \mathrm{mSv}$ and for the skin dose is $1 \mathrm{~Sv}[4,5]$.

The regulatory requirements for the emergency exposure situation described above were established after extensive studies and following accurate procedures and calculations, however, after Fukushima Daiichi Nuclear Power Station (FDNPS) accident it was noticed that working under the emergency situation may take a long unfixed time and workers may exceed their 
dose limits resulting in a negative health effects and their future career options. As a consequence of the Fukushima accident new considerations for the occupational dose criteria in case of the emergency exposure should be taken into account including detailed health, social and economic factors.

\section{MATERIALS AND METHODOLOGY}

In this section the general emergency work classification was linked with the emergency response plan for FDNPS accident. Also TEPCO's (Tokyo Electric Power Company) report for the radiation protection to FDNPS emergency workers was analyzed in order to have an accurate view of what happened during the emergency work and the workers' radiation protection.

\subsection{General Emergency work classification}

Working under emergency condition is classified based on the purpose of the work, that is: (1) immediate action including lifesaving and prevention the accident progression and consequences, (2) implementation of urgent countermeasures affecting the public or application of short term recovery operations, (3) long-term recovery operation, or (4) the work not directly connected to the accident.

Actions involving immediate response to prevent the consequences of the accident including lifesaving ac- tions are usually conducted and more associated to the plant personnel following the accident. It should be noted that in this case, due to the limited time, the optimization of the doses may not be applicable and the individual dose limit may not be relevant.

In the case of the implementation of urgent countermeasures affecting the public or application of short-term recovery operations, these actions can be taken after the radiation sources brought under control to maintain the site essential services and protect other equipment. These kinds of actions may be performed by plants workers and other assistance groups including police, rescue workers, ambulance staff, and evacuation staff.

After the full control of the accident and the restoration of site services, the long-term recovery operations may take part. These actions involve decontamination, waste disposal and any other operations to restore the normal state of the site or make it safe. These actions should not involve a high dose to the workers and in case of possibility of high exposure it should be justified and optimized, since the exposure situation may already be shifted from the emergency exposure situation to the existing exposure situation.

\subsection{Fukushima accident emergency work analysis.}

\subsubsection{TEPCO’s emergency plan [6]}

1- Step'1'and '2': immediately after the occurrence

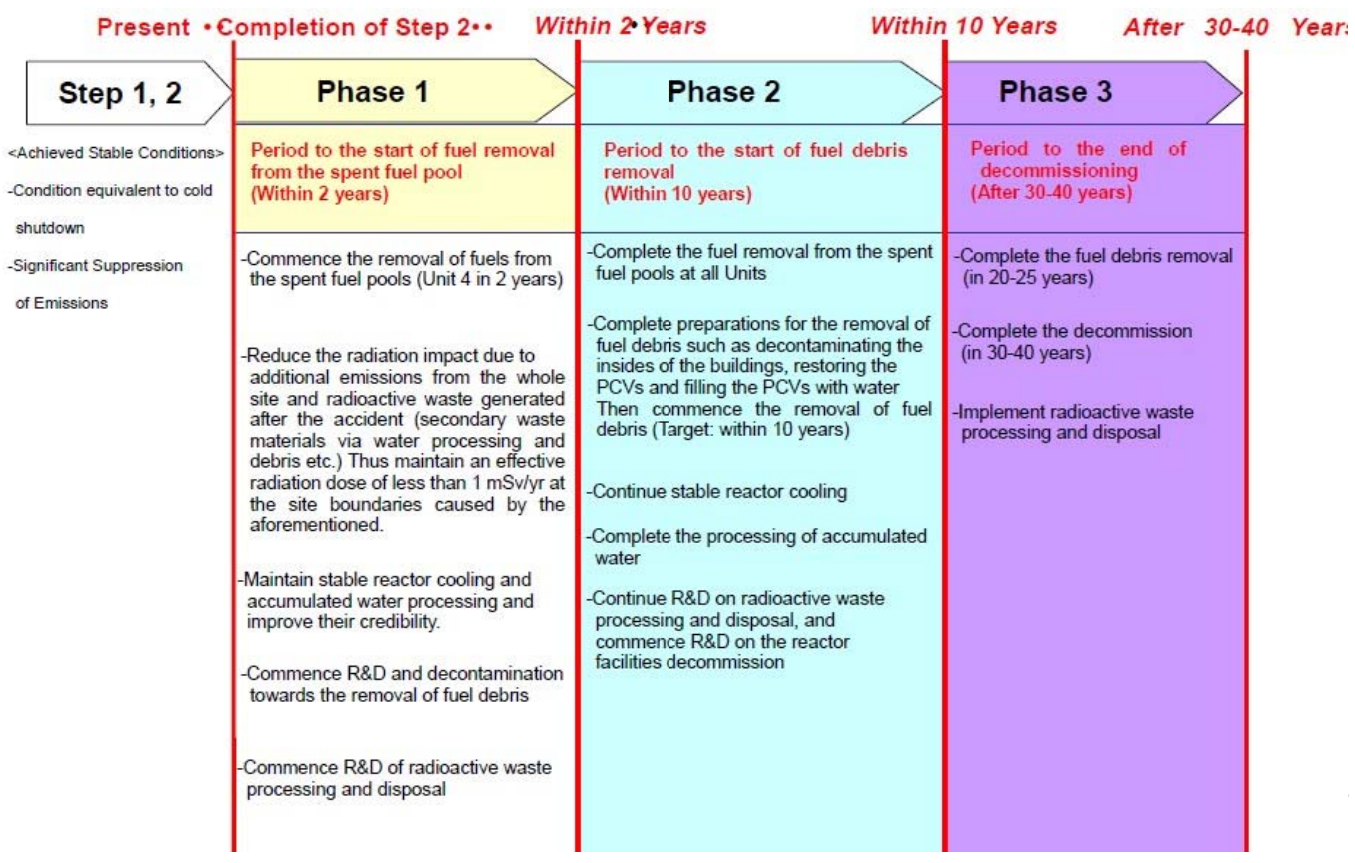

Fig. 1. TEPCO's mid and long-term decommissioning roadmap for FDNPS units 1-4. 
of the accident, achieving stable condition which is equivalent to cold shutdown and the significant suppression of emission.

2- Phase1: after step one achieved, the fuel removal from the spent fuel pool.

3- Phase 2: removal of the fuel derbies.

4- Phase 3: decommissioning of the plant.

A timetable for the mid and long-term decommissioning roadmap for Fukushima Daiichi units 1-4 is shown in Fig. 1.

\subsubsection{Emergency work classification in Fukushima}

Depending on the classification of the emergency work mentioned, the steps and phases above can be classified as follows:

1- Lifesaving or preventing severe consequences actions:

This includes steps 1 and 2 and the workers here are mainly plant personnel. In the case of FDNPS accident the authorities decided to raise the dose criteria to 250 $\mathrm{mSvy}^{-1}$.

2- Short-term recovery operation: This includes steps 1 and 2 including actions necessary performed to maintain essential services. These actions are usually performed by plant workers. The dose criteria related to these actions should not exceed 100 mSv/year.

3- Long-term recovery operation: This includes phases 1, 2 and 3, which can be performed by different parties and authorities. Here the occupational dose limit, which is $100 \mathrm{mSv}$ for 5 years, should not be exceeded and the exposure should be optimized. These actions should be treated as normal operations in terms of the radiological control regime required, and the situation should be regarded as the existing exposure situation.

4- Work not directly connected with an accident. These actions can be performed in any step or phase and are usually encountered the handling of contaminated material not involving high radioactivity.

\subsubsection{Radiation protection control for Fukushima nu- clear power plant workers [7]}

First the situation prior to the earthquake will be described and then compared to the situation after the occurrence of the earthquake and the nuclear accident.

- Radiation protection measures for workers prior to the earthquake

Each worker had to wear an alarm pocket dosimeter (APD) as well as protective clothing and equipment depending on the kind of activity and the level of radi- ation exposure encountered. A system for recording and storing doses after the end of a job was being utilized for the collection of daily individual doses and doses by job type. Individual exposure doses, both external and internal, were managed and a whole body counter (WBC) was periodically taken to evaluate internal doses.

- Radiation protection measures for the workers at post-earthquake situation

As a result of the tsunami, the APD located at the entry management points was submerged with water and with the subsequent power loss, the management systems used for controlling the workers entry and exit, and for the collection of exposure doses lost their function. Furthermore it was decided that all radiation control matters related to the power station would be handled by the emergency response centre (ERC) at the power station located in the seismic isolated building. After the release of radioactive materials, it was decided that all workers should wear the APD and the protective clothing and equipment whenever they leave the seismic isolated building. The seismic building was affected by the hydrogen explosion resulting in its contamination. It was difficult to evaluate the internal exposure using WBC within the facility due to the increase of the background radioactivity.

- Improvement of the environmental condition of the seismic isolated building

As mentioned before this building was the base of operations for handling the FDNPS accident, however after the hydrogen explosion the building was contaminated and efforts were made to improve its condition to protect the emergency workers inside.

The building has only one double door entry/exit, only one door opens at once, the area between the two doors where the place in which the workers remove their protective equipment and check for contamination.

In order to improve the environment inside the building, countermeasures were gradually implemented in addition to charcoal filter ventilation equipment already existed. For example, exhaust fans were installed, and easy decontaminated mats replaced the regular floor mats, these actions resulted in a decrease in air dose rate inside the building.

- Exposure dose standards and screening guidelines in case of emergency

On March 14, 2011 it was decided that the dose criteria in emergency works would be raised from 100 $\mathrm{mSv}$ to $250 \mathrm{mSv}$, because it was clear, depending on the judgment of the working environment, that the accumulated radiation exposure dose was increased 
and there were concerns about the ability to continue accident work within the previous dose criteria. This value $(250 \mathrm{mSv})$ was determined as half of the value stipulated by the ICRP for the urgent rescue operations.

- Reestablishment of the radiation protection framework

A total of 5,000 APDs for the control of the external exposure were found unusable after the tsunami hit the site so that a shortage in the numbers of the APDs for the workers was occurred. It was difficult to provide the dosimeter to each worker, due to this shortage. A representative of each working group was chosen so that this worker may represent the other group members. This can only be applied to works which all workers can move together and the radiation levels are not high. Using this procedure was proven to work appropriately since none of the workers were subjected to excessive radiation exposure.

The radiation exposure levels were recorded by hand when dosimeters returned back to the seismic isolated building. This approach was taken since most of the APDs were unusable by the tsunami and the conventional tallying system was inoperable. The resetting of the APDs was taken by hand too, and cases of incorrect resetting were reported. Furthermore, some cases of an APD returned with dead battery were reported and resulted in inaccurate records.

The internal exposure was taken care by borrowing three mobile NaI scintillation detectors from Japan Atomic Energy Agency (JAEA), mainly used to measure internal exposure of workers involved in support and accident handling outside the nuclear power plant.

In July 2011, one NaI scintillation detector was moved to the FDNPS and other one to $J$ village. In August 2011, 12 whole body counters were installed inside FDNPS, allowing the measurements to be taken once a month.

\section{RESULTS AND DISCUSSION}

\subsection{Distribution of radiation workers exposure [7]}

The average of radiation workers external exposure for 3,765 workers during March 2011 was high at $13.81 \mathrm{mSv}$; however, the average value for 5,128 workers in April 2012 was dropped to 1.07 mSvmonth $^{-1}$, since there was a decreasing trends in fieldwork environmental dose rates.

Two female TEPCO employees exceeded radiation dose limit stipulated by law ( $5 \mathrm{mSv}$ per 3 months).
They were engaged in fire engine refueling in the seismic isolated building, and caring for people who felt ill in the building. Although they took appropriate radiological protection measures, their effective dose exceeded the legal radiation dose limit due to inhalation of radioactive material leaked into the seismic isolated building after the hydrogen explosion. Also six male TEPCO employees exceeded the emergency radiation criteria $(250 \mathrm{mSv})$. They were overexposed due to inhalation and ingestion of radioactive material.

\subsection{Deficiencies in the radiation protection measures during the accident management}

After the analysis of the accident management and the workers' radiation protection procedure some deficiencies were identified and these are listed and categorized as follows:

1) Accident management procedure

a. The seismic isolated building was used as the center of accident management, but it was not fully well prepared.

2) Exposure dose control

a. Insufficient exposure dose control system, the normally used system became inoperable after the tsunami.

b. Insufficient number of the personal dosimeters (APD), 5000 APDs was defected after the tsunami.

c. The dosimeters distribution process to workers was insufficient, reported cases of non-returned dosimeters and dosimeters returned with dead battery.

d. Delay of internal exposure monitoring, whole body counters were lent from JAEA not already existed at the site.

3) Protection equipment and clothes

a. Reported cases of exceeding emergency exposure dose criteria, due to lack of adequate protection measures.

b. Improper use for respiratory protective equipment, reported cases of inhalation of radioactive material.

c. Improper protective clothes used, reported cases of contamination.

4) Workers training

a. Lack of emergency working experience for workers before the accident requiring emergency workers training during the emergency work.

5) Workers health care system

a. Delay in the opening of on-site medical center, due to difficulties in finding practiced qualified 
medical team.

b. Long-term health care for workers who are overexposed should be clearly stated and implemented.

\subsection{Suggestions for the improvement of radiation protection procedure for the emergency workers}

In this part some suggestion are made in order to avoid the problems faced during Fukushima accident management as follows:

1) Determining the dose criteria for workers during accident

Changing the emergency dose criteria for workers from $100 \mathrm{mSv}$ to $250 \mathrm{mSv}$ after the accident occurrence could cause a lot of confusion to workers and the radiation safety organizations. This kind of change of the criteria should be considered in earlier times, during the initial phase of the establishment of the emergency plans and procedure, so that it will be more clear and easily to be applied in case of the accident occurrence.

\section{2) Seismic isolated building design}

The seismic isolated building was used as the base for the accident management and the place for the emergency workers to check their dose levels and contamination. However some deficiencies and shortages were found during the analysis for this building. The building has only one entrance/exit, it has double entry doors with one door closing before the other opens; this area between the two doors was used by workers to remove the protective equipment and then came inside the building to check for contamination. During the initial phase this was the best procedure, however after the hydrogen explosion the building was affected, resulting in a contamination inside the building.

Furthermore, there is no specific place inside the building to isolate the contaminated workers. A case that 30 workers were found contaminated and they temporarily isolated in a conference room, was reported.

When the isolated building was affected by the hydrogen explosion, the air inside was contaminated and further protection measures for the workers inside should be taken, so new particulate and charcoal filters were utilized.

The followings are the suggestions for the improvements of the seismic isolated building:

i- A specific, well-equipped place should be provided to the workers to remove their protective clothes and check for the contamination.

ii- A special place should be designated to isolate the contaminated workers.

iii- The installed ventilation system supplemented by the portable charcoal filters should be prepared for the cases of high air contamination.

3) Protection equipment

After the tsunami a shortage of the dosimeters and detectors was observed, due to the improper isolation and storage of these devices, so that this equipment should be stored in an isolated and well-protected storage facility which can be easily accessible.

4) Radiation dose control

The dose management system should be improved by developing an emergency plan for the case that the normal dose control system is not available. A database should be developed for workers engaged in emergency work or radiation work for the documentation of their medical examination results and the status of their radiation dose control.

5) Workers training

Different types of training such as the training for accident management, especially for the case of multi-units failure situation and the training to use a paper-based dosimeter lending system for the case of the loss of computer-based system, to ensure the workers protection and tracking of their records should be provided to workers.

\section{CONCLUSION}

After analyzing the detailed procedure for Fukushima's accident management and the workers' radiation protection procedure, some deficiencies were identified concerning the accident management procedure, the exposure dose control, the protection equipment and clothes, workers training and workers health care system. Based on the observed deficiencies some suggestions were given in order to avoid such problems in future activities and to protect the emergency workers during their work since it may pose a serious health risks and it could affect their future career choices.

\section{REFERENCES}

1. The International Commission on Radiological Protection (ICRP). Te 2007 recommendations of the ICRP. ICRP Publications 103. 2007.

2. Environmental Protection Agency (EPA). Manual 
for protection action guides and protective actions for nuclear incidents. 1992.

3. U.S. Nuclear Regulatory Commission (NRC). Instruction concerning risks from occupational radiation exposure. Regulatory Guide 8.29. 1996.

4. Kungita N. Radiation Protection and Health Management of Workers in Response to Fukushima Daiichi Nuclear Power Plant Accident. International Conference on Science and Technology for Sustainability. 2013.
5. American Nuclear Society. Fukushima Daiichi ANS committee report. 2012.

6. TEPCO. Mid and Long-Term Roadmap towards the Decommissioning of Fukushima Daiichi Nuclear Power Units 1-4. 2013.

7. TEPCO. Fukushima Nuclear Accident Analysis Report.2012. 